\title{
Effect of Shear Direction on Work-Hardening Evolution of AISI 409 Steel Under Rolling/Shearing Loading
}

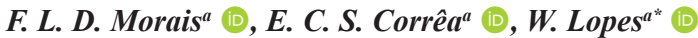 \\ ${ }^{a}$ Centro Federal de Educação Tecnológica (CEFET), Departamento de Engenharia de Materiais, \\ Belo Horizonte, MG, Brasil.
}

Received: August 01, 2021; Revised: November 01, 2021; Accepted: December 28, 2021

\begin{abstract}
The mechanical behavior of metallic materials depends on several variables, such as the material structural characteristics, the process parameters, the temperature, the strain rate and the anisotropy features due to strain paths in different metal forming operations. Considering the last one, the effect of shear direction loading on the work-hardening after the rolling/shearing loading of a ferritic stainless steel, AISI 409, was investigated in this work. The annealed AISI 409 sheets were predeformed by cold rolling up 0.19 effective strain and then sheared at three different directions: at $0^{\circ}, 45^{\circ}$ and $90^{\circ}$ from the original rolling direction. The samples were characterized through tensile, shear and Vickers microhardness tests while the study of crystallographic texture was performed using the electron backscatter diffraction (EBSD) technique. The work-hardening behaviour of the material was analyzed considering the work-hardening rate and the Hollomon work-hardening exponent after each strain path change applied to the AISI 409 steel. The results indicated the presence of preferential crystallographic orientation and the occurrence of transients on the work-hardening rate mainly for the sample sheared at $45^{\circ}$ from the original rolling direction due to structural arrangements assumed by the AISI 409 steel after the strain path changes.
\end{abstract}

Keywords: AISI 409 steel, work-hardening, strain path.

\section{Introduction}

Strain path changes are commonly observed in sheet metal forming such as in punching, bending and deep drawing operations that present linear and non-linear deformation paths. The presence of non-linear deformation paths modifies the hardening behaviour and may reduce the ductility of a material ${ }^{1}$. A change in the strain path during a sheet metal forming process usually produces modifications on the usual mechanical response of different materials, represented by the presence of macroscopic transient effect on the flow stress curve $^{2}$, work-hardening stagnation ${ }^{3}$, permanent softening ${ }^{4}$ and the Bauschinger effect, i.e., a softening phenomenon after stress reversal, associated with the spring back behaviour of the materials ${ }^{5}$.

The intensity of these anisotropic features present in sheet forming operations is significantly affected by parameters such as the amount of prestrain and the subsequent dislocation substructure and density. The crystallographic texture analysis has been showed a good predictive accuracy for the initial anisotropy ${ }^{6}$ and for describing the occurrence of the plastic instability phenomenon detected during strain path changes composed by rolling/shear loading on different shear directions ${ }^{7}$. The loading direction was also associated with the amount of permanent softening in AA3103 aluminum alloy ${ }^{8}$.

These examples show the need to develop an accurate method for describing the mechanical properties of materials submitted to strain path changes. Considering this approach,

*e-mail: wellingtonlopes@cefetmg.br the aim of the present work is the analysis of the effects of shear direction on work-hardening behavior of AISI 409 steel during to the rolling/shear loading.

\section{Materials and Methods}

\subsection{Material and structural analysis}

Annealed AISI 409 ferritic stainless steel sheets $1.0 \mathrm{~mm}$ thick were used in this work. This material is typically used in gas exhaust systems in explosion engines and stamping in general, such as for production of wheel barrows. The chemical composition is shown in Table 1 (weight percent), obtained through optical emission spectrometry (MIP OES).

The microstructural characterization was performed in $10 \mathrm{~mm} \times 10 \mathrm{~mm}$ samples. In this case, conventional metallographic preparation methods were conducted and the chemical attack was carried out with Vilella (1g picric acid, $5 \mathrm{ml}$ concentrated hydrochloric acid and $100 \mathrm{ml}$ PA ethyl alcohol). The analysis and acquisition of images were performed in an optical microscope (OM).

The microstructural investigation was executed for measuring the grain size of the material according to ASTM $\mathrm{E} 112^{9}$ and then to adjust the EBSD analysis. The phase detection of AISI 409 steel was performed in a diffractometer with $\mathrm{Cu} \mathrm{K} \alpha$ radiation $(\lambda=1.5418 \AA)$ with the 2-theta range of $30^{\circ} \sim 130^{\circ}$ with steps of $0.02^{\circ}$, using the PCPDFWIN version 2.2 software from ICDD (International Council for Diffraction Data). 
Table 1. Nominal chemical composition in wt (\%) of AISI 409 steel (MIP OES).

\begin{tabular}{cccccc}
\hline Material & $\mathrm{Cr}$ & $\mathrm{Si}$ & $\mathrm{Mn}$ & $\mathrm{Ni}$ & $\mathrm{C}$ \\
\hline AISI 409 & 11.160 & 0.666 & 0.153 & 0.145 & 0.021 \\
\hline
\end{tabular}

\subsection{EBSD technique}

The effect of preferential crystallographic orientation on the mechanical properties of AISI 409 stainless steel was investigated by EBSD technique. Considering the results shown on the section 3 , the sample sheared at $45^{\circ}$ from the rolling direction was chosen for crystallographic orientation analysis because it exhibited the greatest quantitative change of work-hardening after the strain path change.

The EBSD analysis was performed in a Quanta FEG 3D FEI scanning electron microscope (SEM) with a Bruker QUANTAX EBSD analysis system. Data were processed with the Bruker Esprit 2 software.

Acceleration voltage was set to $15 \mathrm{kV}$ using a magnification of $650 \mathrm{x}$ and the work distance was defined to $10.3 \mathrm{~mm}$. Detection of neighboring grains was set at a disorientation angle of $5^{\circ}$. The area of the specimen was $32330 \mu \mathrm{m}^{2}$ and pixel size $0.32 \mu \mathrm{m}$. $\sim 95.4 \%$ of the points were indexed. The samples for EBSD misorientation analysis were firstly grinded with sandpaper to remove the initial surface, then polished with polishing paste, particle diameters of $2.5 \mu \mathrm{m}$, and $0.5 \mu \mathrm{m}$ and then followed by $5 \mathrm{~h}$ vibratory polishing in Buehler VibroMet 2.

\subsection{Cold rolling and mechanical tests}

Cold rolling was performed in a Frohling rolling mill with $200 \mathrm{~mm}$ diameter cylinders and rolling speed of $6.25 \mathrm{~m} / \mathrm{min}$. This rolling step followed the same initial rolling direction of the material, $0^{\circ} \mathrm{RL}$. The effective (true) von Mises rolling strain, $\varepsilon_{\mathrm{e}}$, was equal to 0.19 , calculated according to Equation 1. This strain value was chosen to allow the establishment of a dislocation density and crystallographic orientation that were typical of this mode of plastic deformation?

$\varepsilon \mathrm{e}=(2 / \sqrt{ } 3) \cdot \ln \left(\mathrm{t}_{0} / \mathrm{t}_{\mathrm{f}}\right)$

Vickers microhardness tests were performed using a load of $200 \mathrm{gf}$, the penetration time was $15 \mathrm{~s}$. These experiments involved 12 indentations in the annealed sample, spaced $0.2 \mathrm{~mm}$ each other being made measurements in two axes, $\mathrm{X}$ and $\mathrm{Y}$, as displayed in Figure 1.

Tensile tests were performed in an Instron 5982 universal testing machine, with Blue Hill 3 control system. In order to acquire deformation values, an automatic Instron 2630100 extensometer was used in the experiments. The cross-head speed was $4.5 \mathrm{~mm} / \mathrm{min}$, leading to an initial deformation rate of $10^{-3} \mathrm{~s}^{-1}$. Yield strength, ultimate tensile strength and uniform elongation values were calculated according to ASTM A370-19 ${ }^{10}$. Three tests for each loading condition were conducted according to ASTM E8/E8M 16a ${ }^{11}$.

The tensile tests were carried with the specimen axis making angles of $0^{\circ}(\mathrm{RD}), 45^{\circ}$ and $90^{\circ}(\mathrm{TD})$ with respect to the rolling direction in order to investigate the anisotropy of the tensile properties. The Lankford values (r-value) at these angles were calculated using the Equation 2, where, w and 1

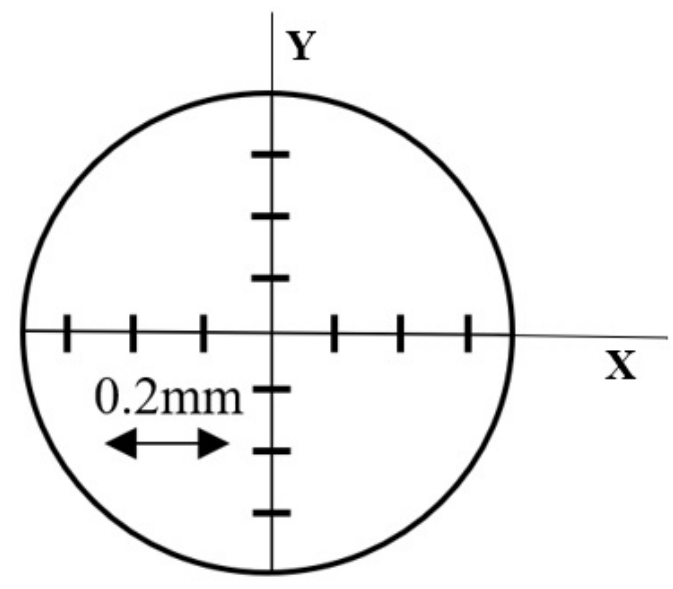

Figure 1. Schematic representation of microhardness Vickers measurements.

are the width and the length strains, respectively, measured on the specimens deformed at a permanent engineering strain of 0.12 . The weighted-average or normal anisotropy $\left(r_{m}\right)$ and the earing tendency or planar anisotropy, $(\Delta r)$ also were calculated according to the Equation 3 and Equation 4, respectively, according to ASTM E517-19 ${ }^{12}$.

$$
\begin{aligned}
& R_{0^{\circ}, 45^{\circ}, 90^{\circ}}=\left(-\varepsilon_{W}\right) /\left(\varepsilon_{w}+\varepsilon_{l}\right) \\
& r_{m}=\left(R_{0^{\circ}}+2 . R_{45^{\circ}}+R_{90^{\circ}}\right) /(4) \\
& \Delta r=\left(R_{0^{\circ}}+R_{90^{\circ}}-2 . R_{45^{\circ}}\right) /(2)
\end{aligned}
$$

The Hollomon strain-hardening strain hardening exponent values ( $\mathrm{n}$ value) and the work-hardening rate, $\mathrm{d} \sigma / \mathrm{d} \varepsilon$, were calculated according to Zandrahimi et al. ${ }^{13}$ considering that diffuse strain localization would be initiated in uniaxial tension and by the effective stress-strain curves from shear tests when $\mathrm{d} \sigma / \mathrm{d} \varepsilon .1 / \sigma$ (normalized work-hardening rate, i.e., work-hardening rate multiplied by the inverse of effective stress) is smaller than unity. The total effective strain at which this occurs can be identified as the strain hardening exponent, $\mathrm{n}$ value.

The shearing tests required a special fixture mounted on the Instron machine, as exhibited in Figure 2. This shear device was designed similarly to one developed by Bouvier et al. ${ }^{14}$. All tests were performed at the same strain rate of tensile tests, $10^{-3} \mathrm{~s}^{-1}$. The shearing specimens were cut with a shearing machine after the rolling step and were $50 \mathrm{~mm}$ long, $20 \mathrm{~mm}$ width and $0.848 \mathrm{~mm}$ thickness. These samples were extracted from the rolled sheet at $0^{\circ}, 45^{\circ}$ and $90^{\circ}$ from the direction of rolling.

The Equation 5 and Equation 6 were used to convert the shearing strains $(\gamma)$, into effective strains $\left(\varepsilon_{\mathrm{e}}\right)$ and the shearing stresses $(\tau)$, into effective stresses $\left(\sigma_{\mathrm{e}}\right)$, respectively. These equations employ the conversion factor of 1.84 , according to recommendations of Rauch ${ }^{15}$.

$\varepsilon \mathrm{e}=\gamma / 1.84$

$\sigma_{\mathrm{e}}=\tau . \mathrm{x} 1.84$ 


\section{Results and Discussion}

\subsection{Microstructural characterization}

OM image and corresponding XRD pattern obtained from the AISI 409 steel sample in the initial state (annealed) of AISI 409 steel are shown in Figure 3. This material displays a ferritic microstructure consisting of fine equiaxed grains with medium size of $44.91 \mu \mathrm{m}$ and Vickers hardness of $130 \mathrm{HV} \pm$ 3.0 HV. The mechanical behavior of AISI 409 steel during the rolling/shear or in other non-linear loadings such as the Bauschinger tests, depends, for example, on the grain size. A large ferrite grain size yields high anisotropy coefficient

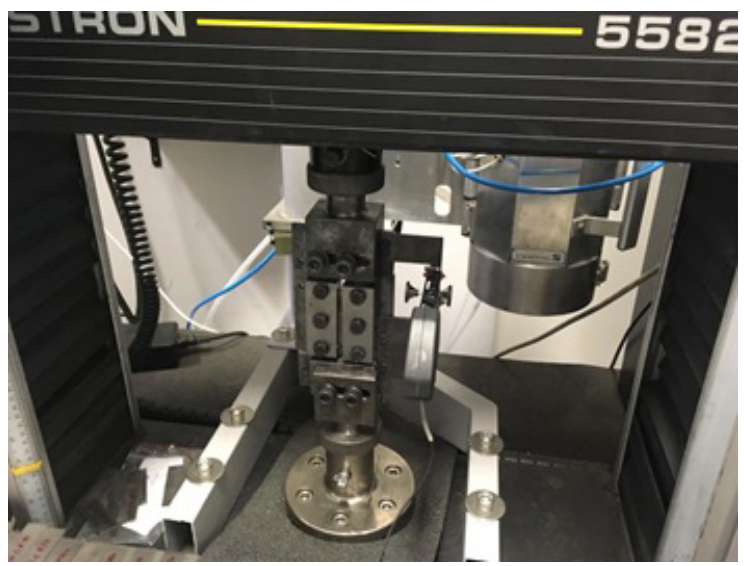

Figure 2. Shear test fixture mounted on the Instron machine. values and also affects the intensity of transients in the work hardening ${ }^{16}$.

\subsection{Characterization in initial state AISI 409 steel}

Figure 4 presents the effective (true) stress-strain curves obtained from tensile and shear testing of AISI 409 steel in the initial state (annealed) at $0^{\circ}, 45^{\circ}$ and $90^{\circ} \mathrm{RD}$. For both modes of characterization, the flow curves were different for each of the 3 directions analyzed, i.e., the AISI 409 steel exhibited an anisotropic behavior.

Under shear loading, the respective curves reached a higher plastic deformation value than that identified in tensile testing. This ability of the shear test to not create a local necking ${ }^{15}$ allowed the identification of the distinct hardening between the three directions analyzed, as can be observed, for example, by the different slope of the curves between the $0^{\circ}$ and $90^{\circ}$ directions and softening with increasing of effective strain for $0^{\circ} \mathrm{RD}$. This behavior suggests a distinct dislocation arrangement at $0^{\circ} \mathrm{RD}$ such as dislocation walls and a progressive reduction in the work-hardening ${ }^{17}$.

The yield strength, (YS), the ultimate tensile strength, (UTS), and the uniform elongation, (UE), values according the tensile specimens orientation with respect to the rolling direction are shown in Table 2. These data reveal that the mechanical strength (ultimate tensile strength) was sensitive to the rolling direction while the ductility wasn't for the initial state of AISI 409 steel.

The anisotropy parameters calculated from tensile testing are exhibited in Table 3. A beneficial condition for sheet stamping can be associated with a high value of $r_{m}$ and

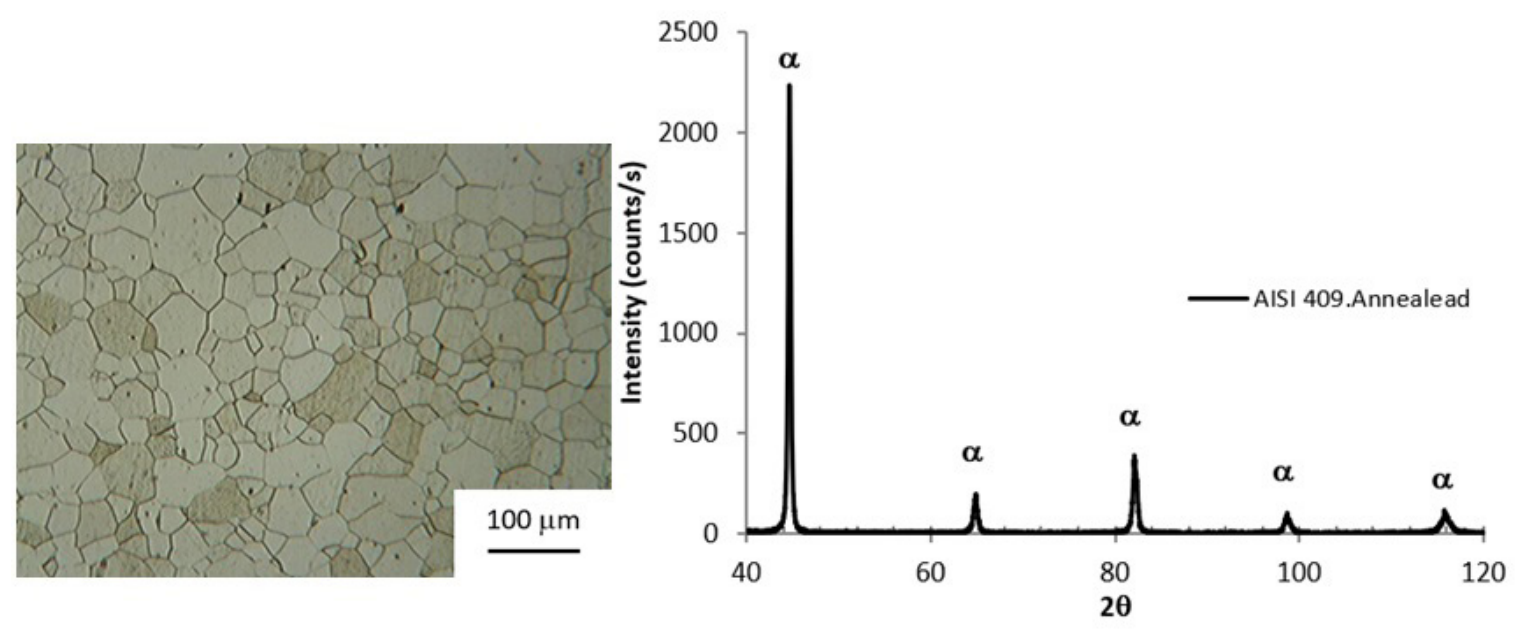

(a)

(b)

Figure 3. (a) Optical microscopy and (b) XRD diffractogram, respectively from annealed AISI 409 steel.

Table 2. Mechanical properties from annealed AISI 409 steel of samples extracted from different angles concerning the rolling direction.

\begin{tabular}{cccc}
\hline Rolling Direction & Yield strength, YS (MPa) & $\begin{array}{c}\text { Ultimate tensile strength, UTS } \\
(\mathrm{MPa})\end{array}$ & \begin{tabular}{c} 
Uniform elongation, UE (\%) \\
\hline $0^{\circ} \mathrm{RD}$
\end{tabular} $2^{\circ} \mathrm{RD}$ \\
\hline $95^{\circ} \mathrm{RD}$ & $201 \pm 4$ & $461 \pm 4$ & $20 \pm 1$ \\
\hline
\end{tabular}




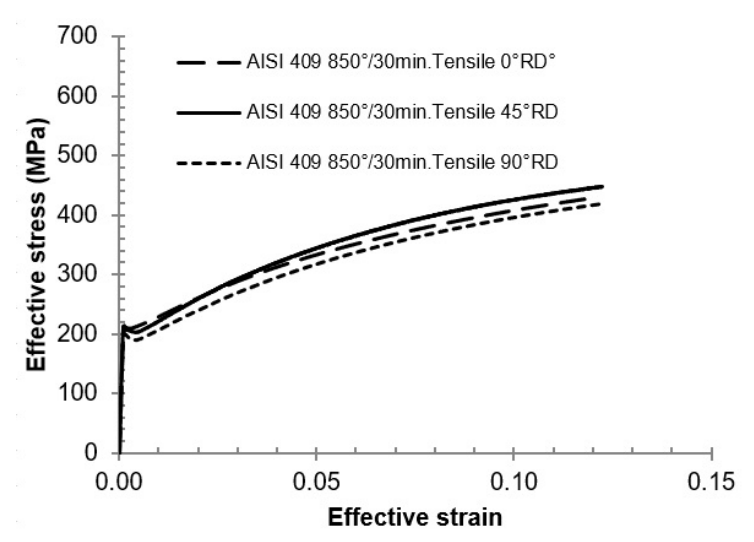

Figure 4. Effective stress-strain curves from annealed AISI 409 at $0^{\circ}, 45^{\circ}$ and $90^{\circ} \mathrm{RD}$.

Table 3. Anisotropy Parameters of AISI 409 Steel.

\begin{tabular}{ccccc}
\hline $\mathrm{R}_{0^{\circ}}$ & $\mathrm{R}_{45^{\circ}}$ & $\mathrm{R}_{90^{\circ}}$ & $\Delta \mathrm{r}$ & $\mathrm{r}_{\mathrm{m}}$ \\
\hline 0.767 & 0.835 & 1.194 & 0.146 & 0.908 \\
\hline
\end{tabular}

a value close to zero for $(\Delta r)^{18}$. These results indicate that the AISI 409 has adequate characteristics for sheet forming processes such as a deep-drawing operations.

The conventional indicators of formability such as the strain hardening exponent, (n), and the normal anisotropy, $\left(r_{m}\right)$, indicate stretchability characteristics for the AISI 409 steel. A high value for $\left(r_{m}\right)$ is necessary, for example, during a deep-drawing operation but it does not influence the sheet metals much when it is subjected to stretching or bending processes ${ }^{18}$. Finally, the reduced $(\Delta \mathrm{r})$ value, 0.146 , suggests a lesser earing tendency for the AISI 409 steel $^{19}$.

\subsection{Rolling/shear loading: mechanical behavior}

Figure 5 presents the effective stress-strain and the corresponding normalized work-hardening rate curves for the rolling/shear loading experiments. In addition to these curves, the monotonic AISI 409 steel curves (annealed condition) is also exhibited in order to compare the effects of strain path changes on the mechanical behavior of this material.

For all shear directions, an initial flow stress increase was observed in comparison with the monotonic effective stress on the annealed condition for the same value of effective strain $\left(\varepsilon_{\mathrm{e}}=0.19\right)$ followed by a reduced normalized workhardening rate and subsequent restoration with the increase in the amount of plastic deformation in shear. This result is typical from a material classified as type 2 after a strain path change $e^{20}$.

The flow stresses at the beginning of shear loading, $\sigma_{\mathrm{f}}$, and the difference between this value in comparison with the flow stress identified in the monotonic loading for the same effective strain $\left(\varepsilon_{\mathrm{e}}=0.19\right), \Delta \sigma$, for each direction are displayed at Table 4 and Figure $5 \mathrm{a}$.

The position of each effective stress-strain curve concerning the initial state of AISI 409 steel (Figure 4) was modified after the rolling/shear loading (Figure 5a). This behavior could be associated to the modifications in structural and crystallographic aspects at the beginning and

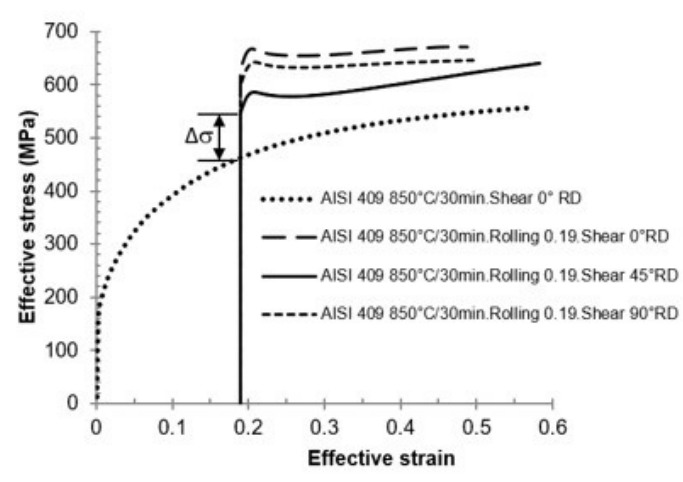

(a)

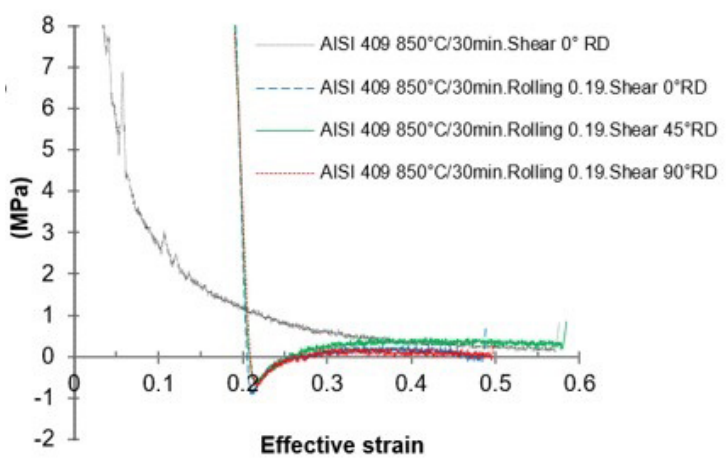

(b)

Figure 5. (a) Effective stress-strain curves from annealed AISI 409 at $0^{\circ} \mathrm{RD}$ and at $0^{\circ}, 45^{\circ}$ and $90^{\circ} \mathrm{RD}$ rolling/shear loading and (b) correspondent normalized work-hardening rate-effective strain curves.

during the continuous deformation in shear ${ }^{7}$. The change in the strain path initially hardened the AISI 409 steel for all directions analyzed, mainly for $0^{\circ} \mathrm{RD}$ direction that exposed the greatest increase in the flow stress, $165 \mathrm{MPa}$.

Otherwise, the loading conducted at $45^{\circ} \mathrm{RD}$ exhibited the smallest increase in the flow stress, $86 \mathrm{MPa}$, being this behavior opposite of that observed under monotonic loading in tensile (Figure 5a). These differences in macroscopic mechanical results suggest the occurrence of crystallographic modifications after the strain path change as observed by Gracio et al. ${ }^{7}$ using pure $\mathrm{Al}$ alloys and Wang et al. ${ }^{21}$.

The normalized work-hardening rate curves exposed the presence of work-hardening transients indicated by the reduction of work-hardening rate and subsequent restoration, Figure 5b. Despite the reestablishment of the work-hardening rate, it is not enough to interrupt the strain localization indicated, i.e., the normalized work-hardening rate is below the unit. This transient occurs for a short interval of effective strain $(\sim 0.037)$ which is very small compared with UE, (the limit of uniform elongation in monotonic loading).

The work-hardening exponents for all shear directions before (monotonic loading) and after (rolling/shear) the strain path change are presented in Table 5. These work-hardening exponents were similar after the strain path change $(\sim 0.20)$ and smaller than the respective monotonic condition value. However, the intensity of the reduction of the work-hardening 
Table 4. Flow stress values, $\sigma_{\mathrm{f}}$, and $\Delta \sigma$ values for the same effective strain value (0.19) for rolling/shear loading.

\begin{tabular}{ccc}
\hline Loading Condition & Flow stress, $\sigma_{\mathrm{f}},(\mathrm{MPa})$ & $\Delta \sigma(\mathrm{MPa})$ \\
\hline Annealed Monotonic $^{\circ} \mathrm{RD}$ & $461 \pm 2$ & 0 \\
\hline Rolling $_{0.19} /$ Shear at $0^{\circ} \mathrm{RD}$ & $626 \pm 3$ & 165 \\
\hline Rolling $_{0.19} /$ Shear at $45^{\circ} \mathrm{RD}$ & $547 \pm 3$ & 86 \\
\hline Rolling $_{0.19} /$ Shear at $90^{\circ} \mathrm{RD}$ & $598 \pm 1$ & 137 \\
\hline
\end{tabular}

exponent was different for each direction, being the highest at $45^{\circ} \mathrm{RD}$.

As mentioned, it was observed an initial flow stress increase in comparison with the monotonic condition at $0^{\circ}$ $\mathrm{RD}$ for all directions after the strain path change (see Figure 5) and the lowest value for the flow stress at the beginning of shear loading was also at $45^{\circ} \mathrm{RD}$. This behavior for $45^{\circ}$ $\mathrm{RD}$ direction can be associated with the establishment of specific structural and texture aspects developed after the rolling/shear strain path change ${ }^{7}$.

The work-hardening transients have been connected to the development of a high density of dislocations with a cellular structure, mainly in metals ${ }^{22}$. Changes in the strain path amplify dislocation activity in secondary slip systems that tend to persist inoperative prior to the onset of these transients. Furthermore, the crystallographic textures tend to become sharp-defined before the onset of transients ${ }^{21}$. These structural changes can be related to the increase in the flow stress and the subsequent decrease and the occurrence of a transient stage in the normalized work-hardening rate observed for AISI 409 steel during the rolling/shear loading.

\subsection{Rolling/shear loading: texture analysis}

The rolling/shear at $45^{\circ} \mathrm{RD}$ loading was chosen for texture analysis because the mechanical results from this direction were different from the other conditions studied in this work such as the magnitude of initial flow stress (lower value) and the occurrence of the highest reduction in work-hardening exponent after the strain path change. Considering this fact, Figure 6 displays the Orientation Imaging Microscopy (OIM) for rolling/shear at $45^{\circ} \mathrm{RD}$ result, exhibiting the rolling direction (RD) and shear direction (SD), a condition where the grains are approximately equiaxed and single colored. Additionally, Figure 7(a) exhibits the grain boundary characteristics and the respective disorientation distribution (Figure 7b).

The grains display a predominance of grain disorientations in the range of $0^{\circ}$ to $5^{\circ}(0.83)$ and $5^{\circ}$ to $15^{\circ}(0.16)$, a low angle grain boundaries (LAGB) condition, and a reduced value in the range $15^{\circ}$ to $60^{\circ}(0.01)$, a high angle grain boundaries (HAGB) condition ${ }^{23}$. For low angle grain boundaries (LAGB), the dislocation distance is large. In this situation, dislocations can be localized as isolated dislocations on a low dislocation density condition and allow the occurrence of softening and transients stages on the normalized work-hardening rate as observed in the rolling/shear loading at $45^{\circ} \mathrm{RD}^{24}$.

The textures for the rolling/shear at $45^{\circ} \mathrm{RD}$ loading are presented in Figure 8 and the ODF sections at $\varphi 2=0^{\circ}$ and $45^{\circ}$ since they contain the most important orientations of the body-centered cubic structure ${ }^{25}$. Pole figures shown in Figure 8 indicate rolling/shear at $45^{\circ} \mathrm{RD}$ intend to create
Table 5. Work-hardening exponents versus loading condition of AISI 409 steel.

\begin{tabular}{cc}
\hline Loading Condition & Work-hardening exponent, $\mathrm{n}$ \\
\hline Monotonic $0^{\circ} \mathrm{RD}$ Annealed & 0.223 \\
\hline Rolling $_{0.19} /$ Shear at $0^{\circ} \mathrm{RD}$ & 0.203 \\
\hline${\text { Monotonic } 45^{\circ} \mathrm{RD} \text { Annealed }}_{0.19} /{\text { Shear at } 45^{\circ} \mathrm{RD}}^{\circ}$ & 0.299 \\
\hline Rolling $^{\circ}$ & 0.204 \\
\hline${\text { Monotonic } 90^{\circ} \mathrm{RD} \text { Annealed }}_{0.19} /{\text { Shear at } 90^{\circ} \mathrm{RD}}^{\text {Rolling }}$ & 0.222 \\
\hline
\end{tabular}

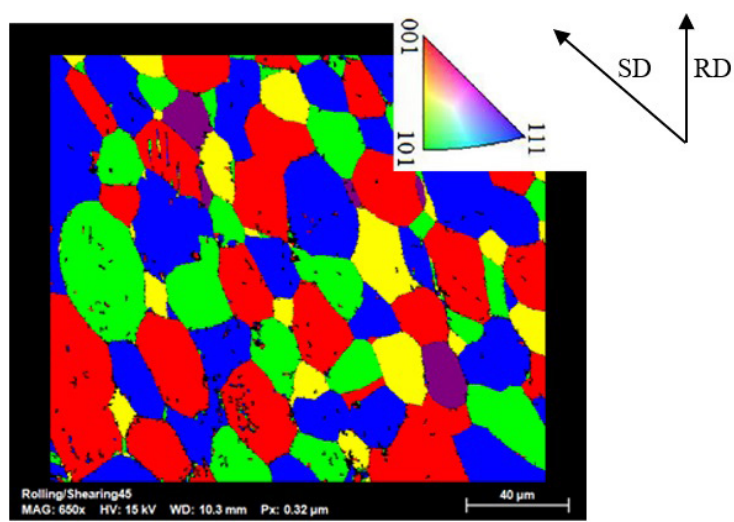

Figure 6. OIM image for AISI 409 after rolling/shear at $45^{\circ} \mathrm{RD}$.

a texture on the $\left\{\begin{array}{lll}1 & 1 & 1\end{array}\right\}$ and $\left\{\begin{array}{lll}1 & 1 & 0\end{array}\right\}$ planes. AISI 409 steel is metal that deform by slip alone and promote a specific orientation, but the intensity is low (0.43), i.e., the Taylor scale underestimates a little the texture ${ }^{26}$.

These results reveal that the crystallographic orientation assumed by AISI 409 at $45^{\circ} \mathrm{RD}$ from rolling/shear loading and the probable respective subestrutural arrangement were responsible by the initial increase in the flow stress at the beginning of shear loading with the subsequent softening and transient stage on the normalized work-hardening rate followed by posterior hardening due to a competition between the subestrutural aspects (that intend to promote an initial hardening on shear tests) and the texture orientation (that tend to soften the material as a result of substructural aspects).

\section{Conclusions}

- The AISI 409 steel exhibited an anisotropic behavior observed in tensile and shear tests with adequate characteristics for a sheet forming processes considering the anisotropy parameters. 


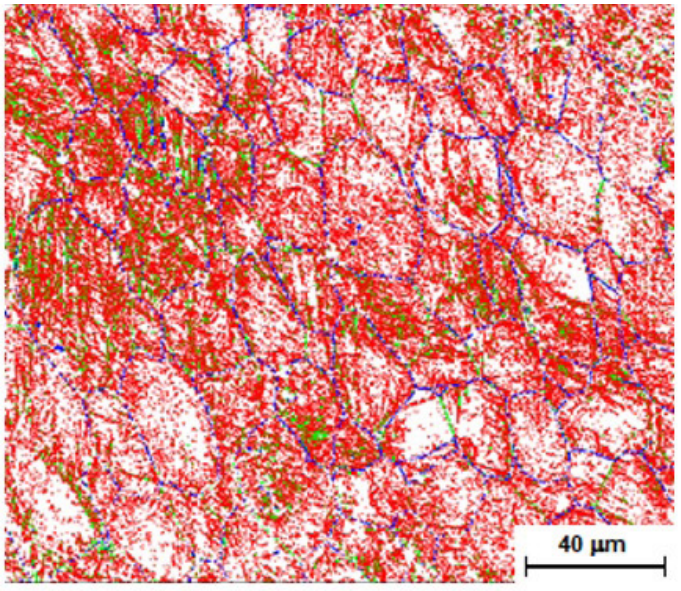

(a)

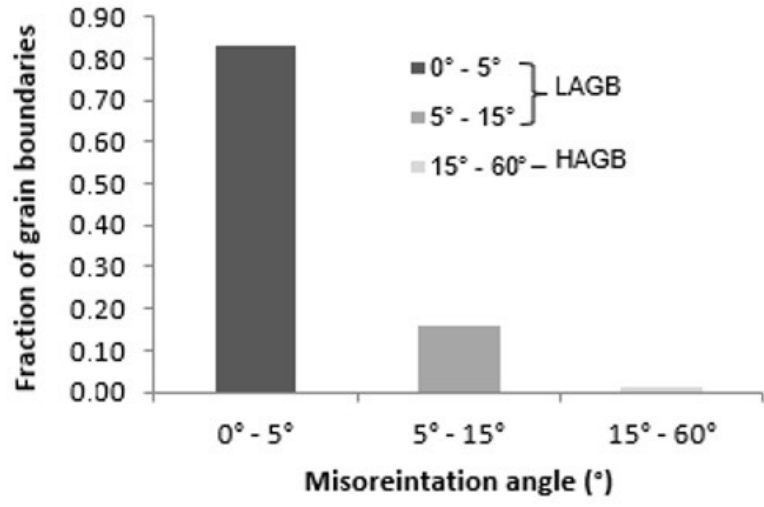

(b)

Figure 7. (a) Grain boundary characteristics and (b) grain disorientation distribution for AISI 409 after rolling $/$ shear at $45^{\circ} \mathrm{RD}$.
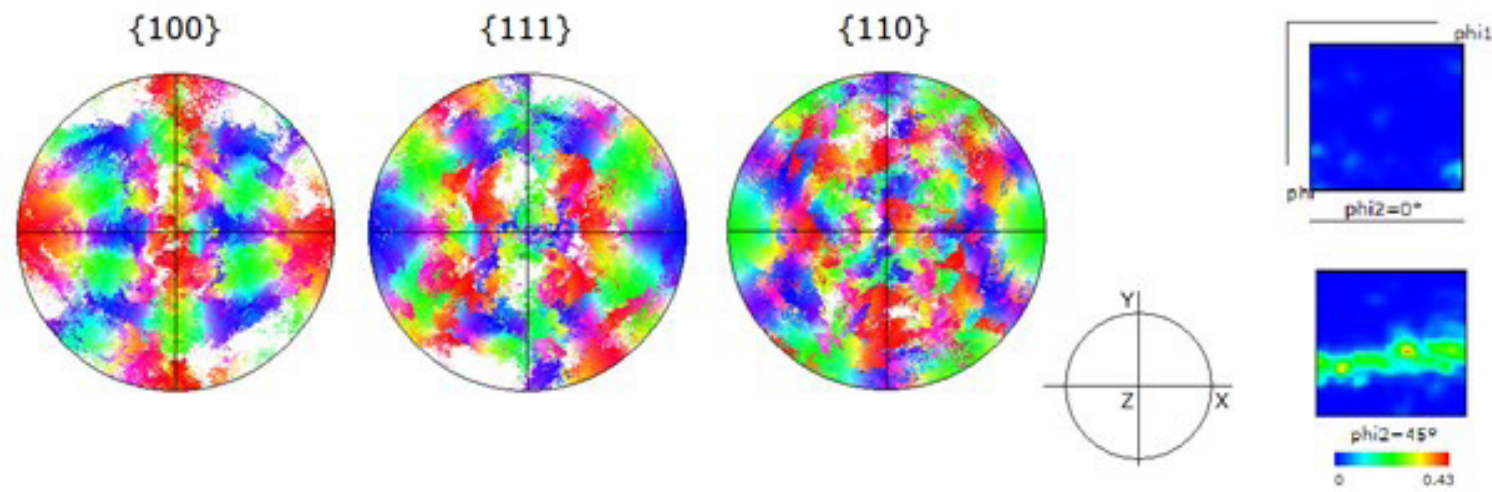

Figure 8. Pole figures for texture for AISI 409 rolling/shear at $45^{\circ}$ and $\varphi_{2}$ sections of orientation distribution function in $\varphi_{2}=0^{\circ}$ and $45^{\circ}$.

- $\quad$ The annealed AISI 409 steel $\left(850^{\circ} \mathrm{C}\right.$ during 30 minutes) was classified as type 2 after the strain path change rolling/shear for $0^{\circ} \mathrm{RD}, 45^{\circ} \mathrm{RD}$ and $90^{\circ} \mathrm{RD}$ directions of shear tests.

- The increase on the initial flow stress and the subsequent reduction of the normalized work-hardening rate were detected for all directions of shear tests on the samples predeformed by rolling.

- The direction of shear tests conducted after the rolling step influenced the occurrence of transients on the normalized work-hardening rate.

- The presence of preferential crystallographic orientation in shear samples extracted at $45^{\circ} \mathrm{RD}$ from the rolling/shear route and the probable substructural arrangements developed by the AISI 409 steel were associated with the initial hardening detected at the beginning of shear tests and the subsequent softening of the sheet.

\section{Acknowledgments}

The authors are grateful to CEFET-MG (Centro Federal de Educação Tecnológica de Minas Gerais), to CNPq (Conselho
Nacional de Desenvolvimento Científico e Tecnológico), to CAPES (Coordenação de Aperfeiçoamento de Pessoal de Nível Superior) and to FINEP (Financiadora de Inovação e Pesquisa).

\section{References}

1. Lee SY, Kim JM, Kim JH, Barlat F. Validation of homogeneous anisotropic hardening model using non-linear strain path experiments. Int J Mech Sci. 2020;183:105769.

2. Lee J, Bong HJ, Kim D, Lee MG. Modeling differential permanent softening under strain-path changes in sheet metals using a modified distortional hardening model. Int J Plast. 2020;133:102789.

3. Ha J, Lee MG, Barlat F. Strain hardening response and modeling of EDDQ and DP780 steel under non-linear strain path. Mech Mater. 2013;64:11-26.

4. Qin J, Holmedal B, Zhang K, Hopperstad OZ. Modeling strain-path changes in aluminum and steel. Int J Solids Struct. 2017;117:123-36.

5. Hetz P, Suttner S, Merklein M. Investigation of the springback behaviour of high-strength aluminium alloys based on cross profile deep drawing tests. Procedia Manufacturing. 2020;47:1223-9.

6. Kim H, Barlat F, Lee Y, Zaman SB, Lee CS, Jeong Y. A crystal plasticity model for describing the anisotropic hardening behavior of steel sheets during strain-path changes. Int J Plast. 2018;111:85-106. 
7. Gracio JJ, Lopes AB, Rauch EF. Analysis of plastic instability in commercially pure Al alloys. J Mater Process Technol. 2000;103:160-4.

8. Qin J, Holmedal B, Hopperstad OS. Experimental characterization and modeling of aluminum alloy AA3103 for complex single and double strain-path changes. Int J Plast. 2019;112:158-71.

9. ASTM International. ASTM E112, Standard Test Methods for Determining Average Grain Size. West Conshohocken, PA: ASTM International; 2013.

10. Qin J, Holmedal B, Hopperstad OS. Experimental characterization and modeling of aluminum alloy AA3103 for complex single and double strain-path changes. Int J Plast. 2019;112:158-71.

11. ASTM International. ASTM E8/E8M, Standard Test Methods for Tension Testing of Metallic Materials ASTM International. West Conshohocken, PA: ASTM International; 2016.

12. ASTM International. ASTM E517, Standard Test Methods for Plastic Strain Ratio r for Sheet Metal. West Conshohocken, PA: ASTM International; 2019.

13. Zandrahimi M, Platias S, Price D, Barret D, Bate PS, Roberts WT, et al. Effects of changes in strain path on work hardening in cubic metals. Metall Trans. 1989;20A:2471-82.

14. Bouvier S, Gardey B, Haddadi H, Teodosiu C. Characterization of the strain-induced plastic anisotropy of rolled sheets by using sequences of simple shear and uniaxial tensile tests. J Mater Process Technol. 2006;174:115-26.

15. Rauch EF. The flow law of mild steel under monotonic or complex strain path. Diffus Defect Data Solid State Data Pt B Solid State Phenom. 1992;23/24:317-34.

16. Feng H, Cai L, Wang L, Zhang X, Fang F. Microstructure and strength in ultrastrong cold-drawn medium carbon steel. J Mater Sci Technol. 2022;20:89-100.
17. Gardey B, Bouvier S, Richard V, Bacroix B. Texture and dislocation structures observation in a dual-phase steel under strain-path changes at large deformation. Mater Sci Eng: A. 2005;400-401A:136-41.

18. Ravi Kumar D. Formability analysis of extra-deep drawing steel. J Mater Process Technol. 2002;130-131:31-41.

19. Vigneshwaran S, Madhavana R, Yoganjaneyulu G, Narayanasamy R. Study of forming and fracture behavior of continuous annealed, batch annealed and cold rolled SS 430 sheet metals. Materials Today: Proceedings. 2020; (In Press). http://dx.doi. org/10.1016/j.matpr.2020.06.032.

20. Chung K, Wagoner RH. Effect of stress-strain law transients on formability. Metall Trans. 1986;17A:1001-9.

21. Wang Z, Rifat M, Saldana C, Basu S. Quantifying the spread in crystallographic textures due to transients in strain path in shot-peening. Materialia. 2018;2:231-49.

22. Mánik T, Holmedal B, Hoppertad OS. Strain-path change induced transients in flow stress, work hardening and r-values in aluminum. Int J Plast. 2015;69:1-20.

23. Lu K. Stabilizing nanostructures in metals using grain and twin boundary architetures. Nat Rev Mater. 2016;1:1-13.

24. Winning M, Rollet AD. Transition between low and high angle grain boundaries. Acta Mater. 2005;53:2901-7.

25. Ray RK, Jonas JJ, Hook RE. Cold rolling and annealing textures in low carbon and extra low carbon steels. Int Mater Rev. 1994;39:129-72.

26. Tóth LS, Massion RA, Germain L, Baik SC, Suwas S. Anlysis of texture evolution in equal channel angular extrusion of copper using a new flow field. Acta Mater. 2004;52:1885-98. 